\title{
Endoscopic submucosal dissection in management of colorectal tumors near or involving a diverticulum: a retrospective case series
}

\section{(ㄷ)(우우}

\author{
Authors \\ Institutions \\ 1 National Cancer Center Hospital, Endoscopy Division, \\ Tokyo, Japan \\ 2 National Cancer Center Hospital East, Division of \\ Endoscopy and Gastrointestinal Oncology, Kashiwa, \\ Japan
}

Victoria Alejandra Jimenez-Garcia ${ }^{1}$, Masayoshi Yamada ${ }^{1}$, Hiroaki Ikematsu², Hiroyuki Takamaru ${ }^{1}$, Seiichiro Abe ${ }^{1}$, Taku Sakamoto' ${ }^{1}$ Takeshi Nakajima', Takahisa Matsuda', Yutaka Saito

submitted 29.6.2018

accepted after revision $\quad 27.12 .2018$

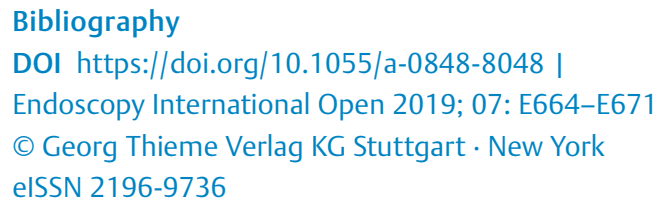

\section{ABSTRACT}

Background and study aims Surgery is the standard treatment for colon tumors associated with diverticulum. Use of endoscopic submucosal dissection (ESD) to treat such tumors is controversial. The aim of this study was to assess the safety and feasibility of ESD in treating superficial colorectal tumors situated near or involving diverticulum. Patients and methods Consecutive patients from two referral centers who had colorectal tumors near or involving diverticulum treated by ESD were retrospectively studied. Clinicopathological characteristics and clinical outcomes were analyzed.

Results Of the 12 patients studied, six had tumors near diverticulum and six had tumors involving diverticulum. The overall en-bloc R0 resection rate, median tumor size and procedure time were $67 \%, 26.5 \mathrm{~mm}$ (range, $15-80 \mathrm{~mm}$ ) and 110 minutes (range, 50-220 minutes), respectively. For tumors near diverticulum group, the en-bloc R0 resection rate was $100 \%$ and no adverse events (AEs) or residual/ recurrent tumors were observed. In contrast, for intradiverticular tumors group, the en-bloc R0 resection rate was low at $33 \%$, and one $\mathrm{AE}$ (perforation) was observed. The diverticula were $\geq 6 \mathrm{~mm}$ in diameter in the patients with incomplete resection. However, all but one diverticulum was unrecognized before ESD. Two residual tumors were detected at the 12-month surveillance and one required surgery.

Conclusions This case series indicates that ESD is safe and feasible for treating colorectal tumors near a diverticulum and might be feasible for tumors involving a diverticulum smaller than $6 \mathrm{~mm}$. Selection for smaller diverticulum size may contribute to higher en-bloc R0 resection rates.

\section{Introduction}

Coexistence of colorectal tumors and diverticulum has been reported [1,2]. Because a colonic diverticulum is a false diverticulum without a muscular layer, tumors involving diverticulum may be diagnosed at advance stages, despite their small size, and may be more rapidly exposed to the serosal surface, possibly contributing to their low survival rate [3].

On the other hand, because they are associated with a negligible risk of lymph node metastasis, colorectal tumors confined to the mucosal layer can be successfully managed by endo- scopic treatments such as endoscopic mucosal resection (EMR) or endoscopic submucosal dissection (ESD) [4]. However, EMR is considered dangerous in cases of diverticula-associated colorectal tumors due to absence of a muscular layer in diverticulum and the consequent increased risk of perforation [5].

ESD allows en-bloc resection of colorectal tumors using electrosurgical knives under direct visualization [6]. ESD also allows precise pathological diagnosis of the resected specimen. These are beneficial factors in management of colorectal tumors associated with a diverticulum because tumors can di- 
rectly invade the serosa in this uncommon location [3,7]. Although several individual cases of ESD treatment of such colonic tumors have been reported [8-14], use of ESD for treating a colonic tumor found near or involving a diverticulum remains controversial. Here, we report on a series of 12 consecutive patients with colorectal tumors near or involving a diverticulum treated by ESD.

\section{Patients and methods}

From December 2004 to February 2017, we performed ESD in 12 consecutive patients who had colorectal tumors near or involving a diverticulum. The procedures were performed at the National Cancer Center Hospital, Tokyo, Japan, and at the National Cancer Center Hospital East, Chiba, Japan. We retrospectively analyzed patients' clinicopathological features and clinical outcomes. This case series was approved by the Institutional Review Board of the National Cancer Center.

\section{Classification of colorectal tumors related to the diverticular orifice}

All tumors were divided into two groups ( $>$ Fig. 1):

- Near type - The tumor reached the diverticular border, but did not enter the diverticular orifice.

- Involving type - The tumor reached and entered the diverticular orifice; when the lesion fully covered the diverticulum, the diverticulum was unrecognized before ESD was performed.

\section{Endoscopic diagnosis}

All diagnostic colonoscopies were performed using magnifying colonoscopes (CF-HQ290AZI, CF-H260AZI, CF-FH260AZI, PCFQ260AZI or PCF-Q240ZI, Olympus, Tokyo, Japan).

After white-light observation, narrow-band imaging (NBI) with magnification and chromoendoscopy was performed to determine the pit pattern of the tumor [15] to assess whether it was suitable for ESD. If a diverticulum was detected, careful examination was performed to determine the size of the diverticulum and the pit pattern of the tumor involving the diverticulum. A short-type ST hood (DH-28GR Fujifilm Medical Co., Tokyo, Japan) was used to measure the size of diverticulum. Biopsy was not performed before ESD because that could cause fibrosis, which might interfere with submucosal lifting.

\section{ESD procedure}

Details of the ESD technique have been described previously [6]. All procedures were performed using a therapeutic endoscope with a water-jet function and carbon dioxide insufflations. A short-type ST hood (DH-28GR Fuji film Medical Co., Tokyo, Japan) was used for traction and to obtain good field visualization for cutting the submucosal layer. An electrosurgical knife (Ball-tip bipolar needle knife [B-knife or jet B-knife; XEMEX Co, Tokyo Japan]), a Dual knife (Olympus Optical Co, Tokyo, Japan) and/or an insulation-tipped knife nano (IT-Knife nano, Olympus Optical Co, Tokyo, Japan) was used during ESD procedures. Glyceol (Chugai Pharmaceutical Co., Tokyo, Japan) and MucoUp (Johnson and Johnson, Tokyo, Japan) were used for submucosal injection.

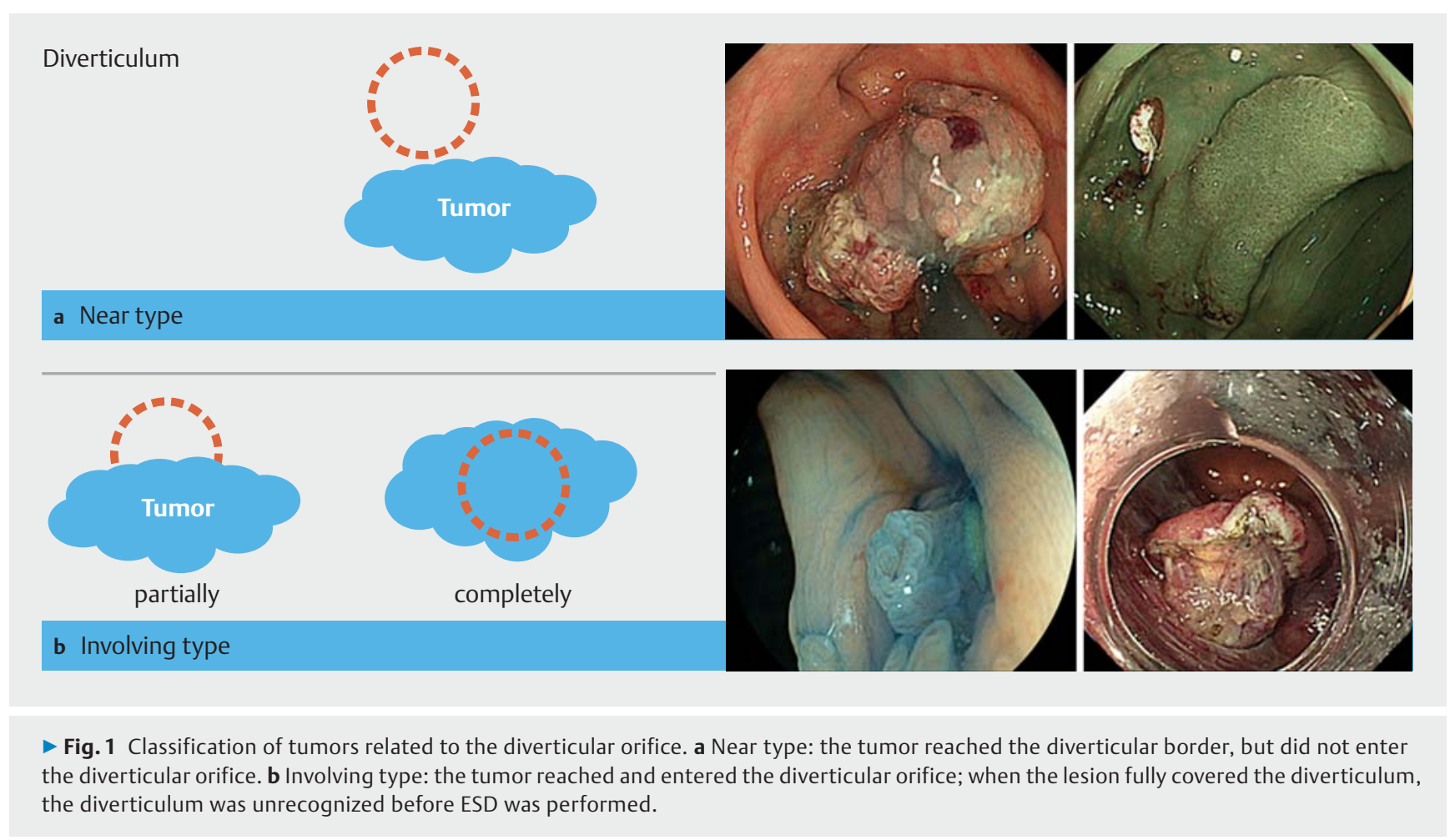


In the near type group, submucosal injection and mucosal incision were started nearest to the diverticulum, where the tumor and diverticulum were closest together. Then, ESD was continued from the periphery of the diverticulum to the opposite side to complete the procedure.

In the involving type group, submucosal injection and mucosal incision were started with a standard approach. We tried to dissect the submucosal layer early in the procedure for easier lifting. However, in cases in which the tumor completely covered the diverticulum, it was not recognized before ESD. A traction device, a silk line tied to the arm of a clip, was used as required $[16,17]$. The submucosal side of the targeted specimen was grasped under clear visualization and the line was pulled very gently. Polypectomy, strip biopsy [18], argon plasma and elastic band ligation (EBL) were used as required to complete resection in the intradiverticular area. Experienced endoscopists performed the procedures (MY, HI, HT, SA, TS, TN, TM and YS).

\section{Histopathological evaluation}

Resected specimens were stretched and fixed in $10 \%$ formalin and then cut into 2-mm slices. Histological type, depth of invasion, and lymphovascular invasion were evaluated according to World Health Organization classification [19]. R0 resection was defined histopathologically as tumor-free lateral and vertical margins. $\mathrm{R} 1$ resection was defined by presence of tumor cells in the resection margin. Complete resection was defined as en-bloc R0 resection. Patients whose specimens did not fulfill the criteria for complete resection were classified as incomplete resection.

\section{Follow-up}

Patients with incomplete resection after ESD had intensive follow-up with colonoscopy and computed tomography (CT) scans as required every 3 to 6 months. Patients with complete resection post-ESD were followed up with annual colonoscopy and CT scans as required.

\section{Results}

Clinicopathological characteristics and ESD procedure technical outcomes for the 12 patients with colorectal tumors near or involving diverticulum are summarized in $>$ Table 1 .

None of the patients had a previous history of diverticulitis. Of the 12 patients, in six patients, the tumor was near a diverticulum and in the other six patients the tumor was involving a diverticulum. Pre-ESD endoscopic depth diagnosis showed dysplasia in 12 patients, with a median tumor size of $26.5 \mathrm{~mm}$ (range, $15-80 \mathrm{~mm}$ ). The tumors were all classified as type $2 \mathrm{ac}-$ cording to the NBI International Colorectal Endoscopic (NICE) classification [20,21]. Kudo's pit pattern classification identified two tumors as type IIIL, one as type IV with serration features, two as type IV without serration features and seven as type $V_{1}$. In four patients, the diverticulum was not detected in the tumors prior to ESD. Median procedure time for ESD was 110 minutes (range, 50-220 minutes). En-bloc R0 resection was achieved in eight of 12 patients (67\%). In the near type group, all the diverticula were recognized before ESD; whereas, in the involving type group, diverticulum were recognized in only two cases prior to ESD.

In the near type group, median procedure time was 110 minutes (range, 60-220 minutes) and en-bloc resection was achieved in $6 / 6$ patients (100\%). There were no adverse events (AEs) and no residual/recurrent tumor was detected during the follow-up period (median, 16.5 months; range, 12-60 months). In contrast, among the involving type group, median procedure time was 90 minutes (range, 50-210 minutes) and en-bloc resection was achieved in $2 / 6$ patients $(33 \%)$. In the other four patients, resection had to be performed peacemeal because of intradiverticular tumor extension; strip biopsy ( $>$ Fig. 2), band ligation, polypectomy and/or argon plasma coagulation were required in these cases. In all but one case, intradiverticular extension was $100 \%$. Therefore, we used traction with the "clip with line method" [16] in that patient to achieve complete resection ( $\mathbf{F i g . 3}$ ).

To prevent delayed perforation, the diverticulum was closed in five of the 12 patients and excision sites were completely closed with endoclips in two cases. Tattoo was performed in one case in the involving type group due to a suspicion of submucosal invasion.

In regards to $\mathrm{AEs}$, only one patient in the involving type group $(1 / 6,17 \%)$ developed a pin-hole perforation in the diverticulum during the procedure, which was immediately successfully closed using endoclips (HX-610-090; Olympus Medical Systems Corp., Tokyo, Japan), and only in that case was the serosa visualized. After clip closure, the patient had no fever or abdominal pain. There were no other AEs and no cases required emergency surgery.

All ESD scars were clearly recognized during follow-up. Residual tumors were detected in two patients (2/6, 33\%; patients 8 and 9) during the follow-up period (median, 12 months; range, 3-12 months). In patient 8 , the tumor was tiny and was successfully ablated by hot biopsy. Patient 9 required additional surgery because residual tumor at the diverticulum had become large by the time of the 12-month surveillance colonoscopy. No stricture was detected in the area of endoscopic treatment during follow-up and all the diverticula had disappeared within the scars.

\section{Discussion}

This is the first referral center case series of colorectal tumors arising near or involving a diverticulum treated using ESD. The overall en-bloc R0 resection rate in this series of 12 patients was $67 \%$, with a clear dichotomy between the rate for tumors near a diverticulum (100\%) and those involving a diverticulum (33\%). Therefore, ESD is considered a feasible treatment for colorectal tumors near a diverticulum. Indeed, there were no cases of delayed perforation or bleeding and no emergency surgeries were required. In contrast, in addition to the low en-bloc resection rate in tumors involving a diverticulum, two of these patients were found to have residual tumor at the time of first surveillance colonoscopies. Therefore, ESD may be considered more challenging as a treatment in this group. 


\begin{tabular}{|c|c|c|c|c|c|}
\hline 울 & 울 & 울 & 울 & 울 & 울 \\
\hline$\stackrel{N}{\sim}$ & $\stackrel{m}{\square}$ & 아 & 이 & $\stackrel{\curvearrowright}{\sim}$ & $\stackrel{m}{r}$ \\
\hline$\Sigma$ & $\Sigma$ & $\Sigma$ & $\Sigma$ & $\Sigma$ & $\sum_{n}$ \\
\hline 웜 & ن & ن & 옹 & తి & $\frac{\bar{c}}{\frac{2}{2}}$ \\
\hline
\end{tabular}

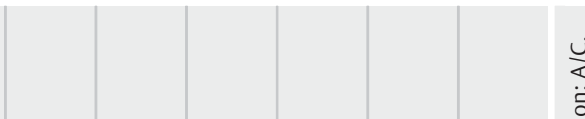

咅 $\overline{\mathrm{E}}$

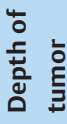

के

要

篦

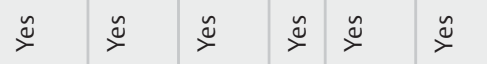

莺

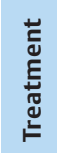

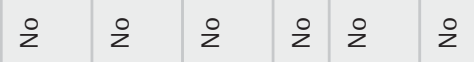

$\stackrel{\circ}{z} \quad \stackrel{0}{z} \quad \stackrel{0}{z} \quad \stackrel{0}{z}$

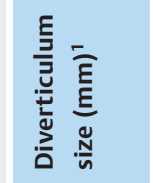

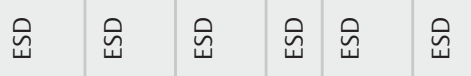

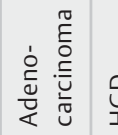

ิㅗㄴ

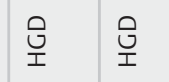

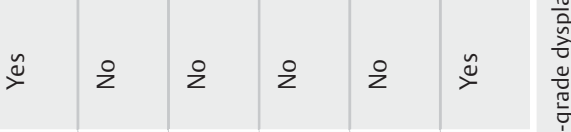

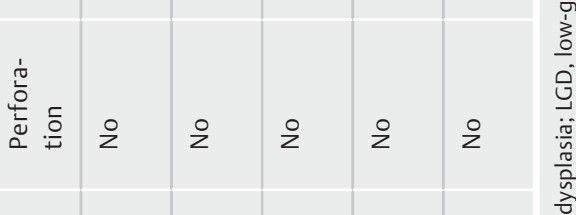

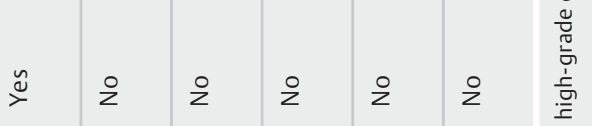

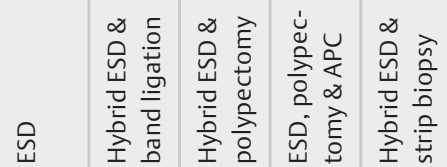

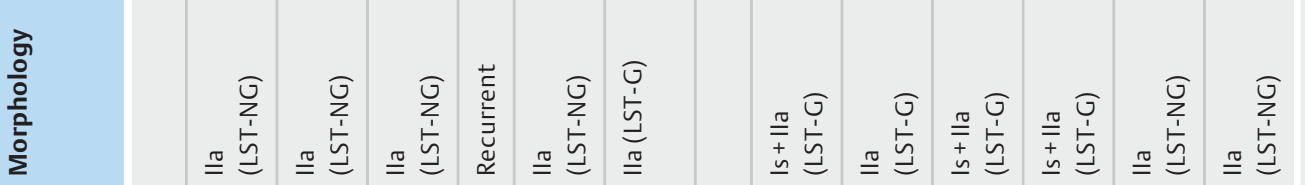

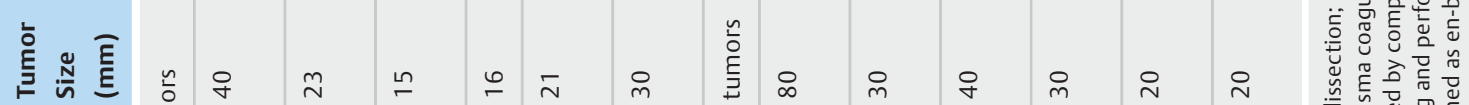



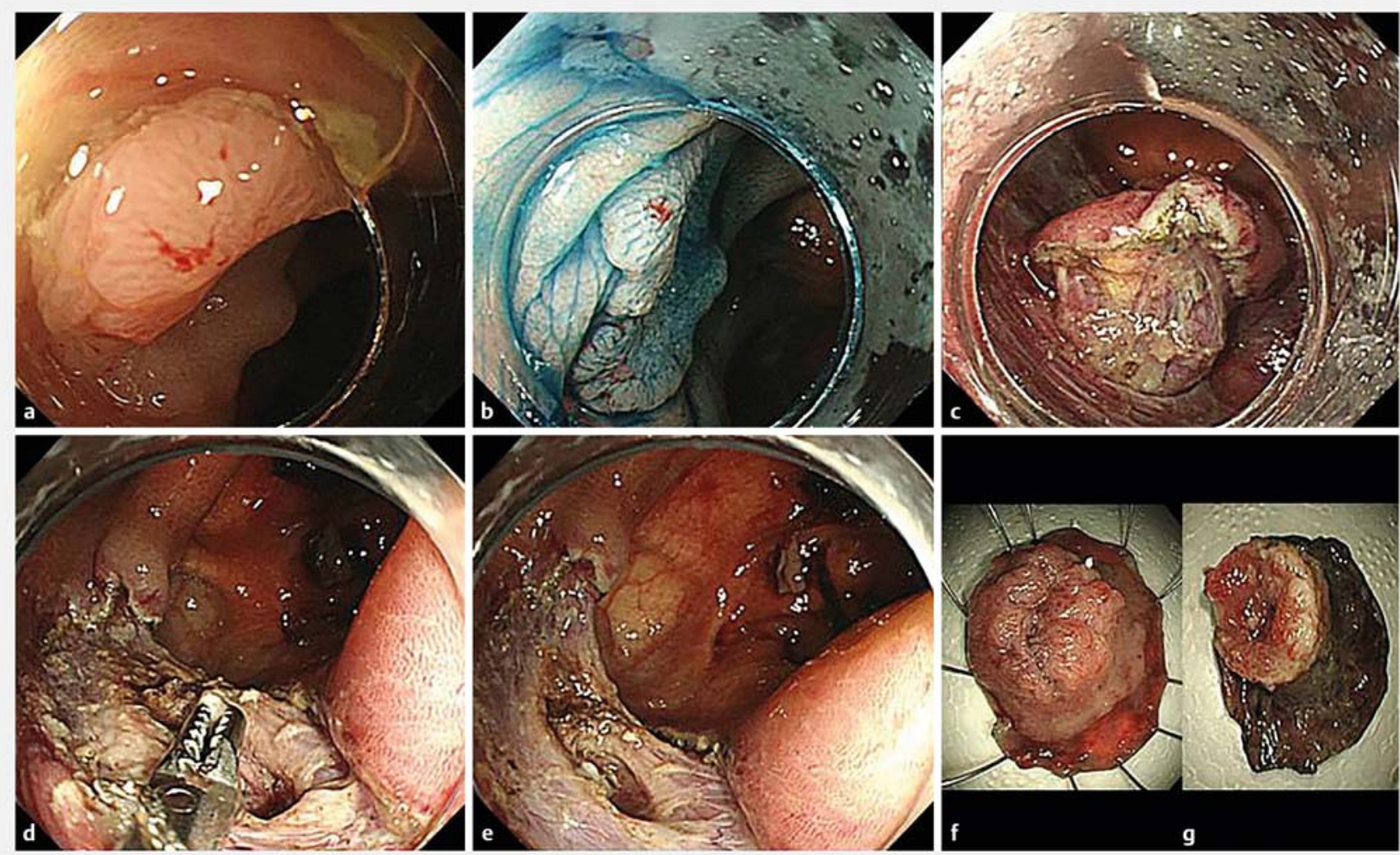

Fig. 2 a A 20-mm LST-NG tumor was detected in the cecum. b Characterized as tumor type $V_{1}$ Kudo's pit pattern, the tumor was resected initially by ESD. c During the ESD procedure, it was observed that the tumor was involving completely a diverticulum. $\mathbf{d}$ Hybrid ESD with strip biopsy was necessary. e Finally, the lesion was resected in piecemeal. f Resected specimen (mucosal side). g Resected specimen (submucosal side). ESD, endoscopic submucosal dissection; LST-NG, laterally spreading tumor-non-granular.

ESD has resulted in high en-bloc resection rates in previous studies with accurate pathological evaluations (88\%-95\%) [6, $22,23]$. In addition, long-term clinical outcome studies have shown near-zero recurrence rates if ESD achieved complete resection without unfavorable histological features [24,25]. In line with previous studies, our en-bloc R0 resection rate was $100 \%$ in patients with tumors near diverticulum, with no recurrences. In contrast, the en-bloc resection rate was low (33\%), and incidence of residual/recurrent tumor was high (33\%) in patients with tumors involving diverticulum. Furthermore, difficult recognition of tumor within diverticulum before ESD is a very serious problem. Indeed, all but one diverticulum was unrecognized before ESD. In those cases, we suggest that ESD combined with other techniques, such as traction devices, endoscopic band ligation (EBL) and endoscopic full-thickness resection using over-the-scope clip (EFTR-OTSC), may improve treatment outcomes $[10,14,26]$. Indeed, good visualization and traction in the submucosal layer can be obtained with use of traction devices $[16,17]$. In the current study, a traction device helped us achieve en-bloc resection in one patient with a tumor involving diverticulum. Three isolated reports also suggested that traction devices were successful in facilitating the procedure. $[8,11,14]$. In addition to near and involving type, diverticulum size also was considered as a potentially an important factor in achieving en-bloc resection. All four pa- tients with incomplete resection had tumors involving a diverticulum. In all of the incomplete resection cases, diverticulum size was $\geq 6 \mathrm{~mm}$, larger than in the complete resection cases (range, 3-5 mm; $>$ Table 1 ).

To prevent delayed perforation, the diverticulum was closed in three of the six involving-type cases. All ESD scars were clearly recognized during follow-up and all diverticula had disappeared within the scars. Residual lesions were detected in two patients whose diverticulum had not closed. Therefore, if there is a possibility of residual tumor, it is better to not close the diverticulum. In such cases, EBL and EFTR-OTSC might be applied. Intensive follow-up of these patients with colonoscopy and computed tomography scans is necessary.

There have been seven isolated case reports describing ESD for colorectal tumors associated with diverticulum; in six cases the tumors involved a diverticulum and in one case the tumor was near a diverticulum [8-14]. In only one of these cases was failure to achieve en-bloc resection reported, and that was in a patient with a tumor involving a diverticulum. Also, local peritonitis was reported in one case within a diverticulum and improved 3 days after ESD with conservative management. Conventional EMR is a promising strategy for colorectal dysplasia [27]. However, if there is a diverticulum, EMR has risk of perforation or incomplete resection $[5,7,13]$. It is difficult to see the cutting point during EMR. Notably, four of the six cases of 

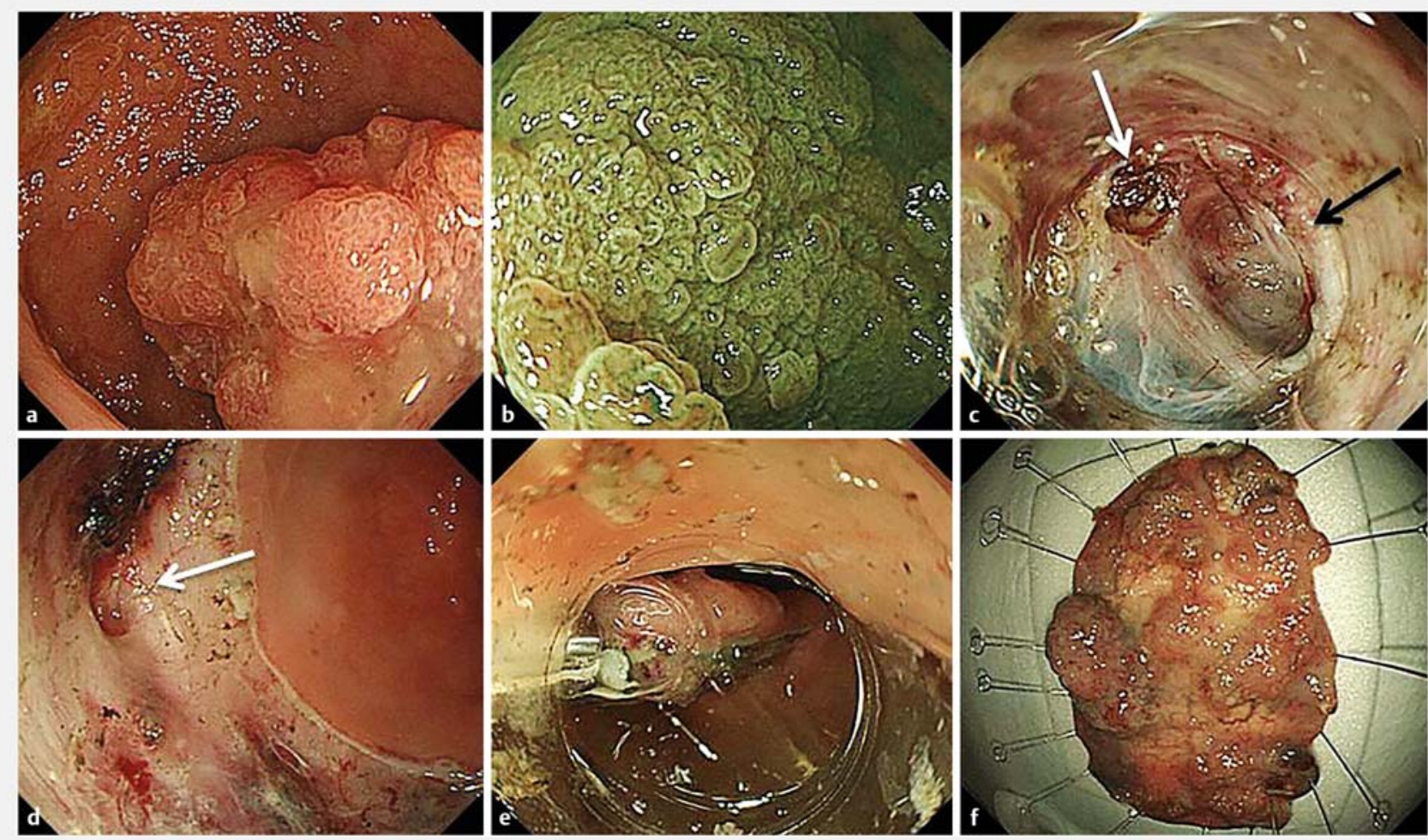

- Fig. 3 a An 80-mm LST-mixed tumor, Sano type 2, was detected in the sigmoid colon. b Characterized as tumor type IV Kudo's pit pattern with serrated features, the tumor was resected by ESD. c,d During the procedure, it was observed that the lesion was involving a diverticulum (black arrow), and in addition, a pin-hole perforation was detected (white arrow). e A traction technique was used with a clip and silk line. f Finally, the lesion was resected en-bloc. ESD, endoscopic submucosal dissection; LST, laterally spreading tumor.

- Table2 Non-ESD techniques reported for resection of involving-diverticulum type tumors.

\begin{tabular}{|c|c|c|c|c|c|c|c|c|c|c|}
\hline Author & $\begin{array}{l}\text { Tumor } \\
\text { location }\end{array}$ & $\begin{array}{l}\text { Tumor } \\
\text { size } \\
(\mathrm{mm})\end{array}$ & $\begin{array}{l}\text { Diverti- } \\
\text { culum } \\
\text { size } \\
(\mathrm{mm})\end{array}$ & $\begin{array}{l}\text { Diverticu- } \\
\text { lum identi- } \\
\text { fied before } \\
\text { treatment }\end{array}$ & $\begin{array}{l}\text { Treat- } \\
\text { ment }\end{array}$ & $\begin{array}{l}\text { Adverse } \\
\text { events }\end{array}$ & $\begin{array}{l}\text { Com- } \\
\text { plete } \\
\text { resec- } \\
\text { tion }{ }^{1}\end{array}$ & $\begin{array}{l}\text { Diverti- } \\
\text { culum } \\
\text { closure }\end{array}$ & Follow-up & $\begin{array}{l}\text { Residual } \\
\text { or recur- } \\
\text { rent } \\
\text { tumor }\end{array}$ \\
\hline $\begin{array}{l}\text { Mori H, et al. } \\
{[30]}\end{array}$ & Sigmoid & 25 & $\mathrm{~N} / \mathrm{E}$ & No & $\begin{array}{l}\text { EMR+ } \\
\text { OTSC }\end{array}$ & No & Yes & Yes & No & $\begin{array}{l}\text { No } \\
\text { follow-up }\end{array}$ \\
\hline $\begin{array}{l}\text { Carmo J, et al. } \\
\text { [31] }\end{array}$ & Sigmoid & 6 & $\mathrm{~N} / \mathrm{E}$ & Yes & EBL & No & 2 & No & 2 weeks & No \\
\hline $\begin{array}{l}\text { Pinho R, et al. } \\
\text { [32] }\end{array}$ & Sigmoid & 10 & $\mathrm{~N} / \mathrm{E}$ & Yes & $\begin{array}{l}\text { Endo- } \\
\text { loop }\end{array}$ & No & 2 & Yes & 2 months & No \\
\hline $\begin{array}{l}\text { Shakhatreh } \\
\text { M, et al. [33] }\end{array}$ & $\mathrm{T} / \mathrm{C}$ & 10 & $\mathrm{~N} / \mathrm{E}$ & Yes & $\begin{array}{l}\text { EBL+ } \\
\text { OTSC }\end{array}$ & No & Yes & Yes & No & $\begin{array}{l}\text { No } \\
\text { follow-up }\end{array}$ \\
\hline $\begin{array}{l}\text { Valli P, et al. } \\
\text { [34] }\end{array}$ & $\mathrm{A} / \mathrm{C}$ & 13 & $\mathrm{~N} / \mathrm{E}$ & Yes & OTSC & No & Yes & Yes & 3 months & No \\
\hline
\end{tabular}

ESD, endoscopic submucosal dissection; T/C transverse colon; A/C, ascending colon; N/E, not specified; EMR, endoscopic mucosal resection; OTSC, over-the-scope clip; EBL, elastic band ligation.

${ }^{1}$ Complete resection was defined as en-bloc resection with tumor-free margins on pathological assessment (R0).

2 Specimen not obtained.

near type were smaller than $25 \mathrm{~mm}$ in the current study. However, five of six were lateral spreading tumors-non-granular type (LST-NG) and the remaining 16-mm case was a recurrent tumor after incomplete EMR. It has been reported that LST-NG lesions have a higher rate of submucosal invasion [28]. Given the possibility of increased fibrosis, EMR would not have been 
an effective alternative [29]. Therefore, we believe that ESD is a safer option, as long as the cutting point can be directly visualized.

"Non-ESD" techniques for resection of tumors arising in diverticulum have been reported [30-34] ( $\triangleright$ Table 2). EBL is a minimally invasive procedure that may be safe and effective for treating tumors involving a diverticulum, but tumor size no doubt is a limitation, and no specimen is obtained for histopathological analysis. The ligate-and-let-go-technique using an endoloop has been described mainly for treating lipomas in the small bowel and colon; however, as with EBL, a specimen is not obtained for histopathological study. Laparoscopic-assisted colorectal (LAC) surgery is one option for tumors involving a diverticulum. However, when we compared incidence of AEs (e. g., wound infection, leakage, ileus), procedure time, procedure invasiveness, hospitalization length, and cost for LAC procedures versus ESD procedures, the improved safety profile and the possibility of curative treatment with ESD provided advantageous in treating dysplasia [35].

This study had some limitations. First, it was retrospective and observational, performed in two referral centers and lacking in a control group. Second, all procedures were performed by experienced Japanese endoscopists, which could be a limitation. However, use of ESD has been spreading worldwide and good outcomes with it have been reported. Results of this study with use of ESD for tumor near the diverticulum are generalizable. Regarding ESD for tumor involving diverticulum, accumulation of traction-assisted ESD cases is expected.

\section{Conclusion}

The case series presented here indicates that ESD is safe and feasible for treatment of colorectal tumors near a diverticulum and might be feasible for tumors involving a diverticulum smaller than $6 \mathrm{~mm}$. Small diverticulum size may be a predictor of better outcome for ESD treatment of tumors involving a diverticulum.

Competing interests

None

\section{References}

[1] Prescott RJ, Haboubi NY, Dunaway DJ et al. Carcinoma arising in a diverticulum of sigmoid colon. Histopathology 1992; 21: 387-389

[2] Kobayashi N, Hirabayashi K, Matsui T et al. Depressed-type colon cancer in a patient with diverticulosis. Endoscopy 2008; 40: (Suppl. 02): E44

[3] Cohn KH, Weimar JA, Fani K et al. Adenocarcinoma arising within a colonic diverticulum: report of two cases and review of the literature. Surgery 1993; 113: 223-226

[4] Matsuda T, Fujii T, Saito Y et al. Efficacy of the invasive/non-invasive pattern by magnifying chromoendoscopy to estimate the depth of invasion of early colorectal neoplasms. Am J Gastroenterol 2008; 103 : $2700-2706$
[5] Fu KI, Hamahata Y, Tsujinaka Y. Early colon cancer within a diverticulum treated by magnifying chromoendoscopy and laparoscopy. World J Gastroenterol 2010; 16: 1545-1547

[6] Saito Y, Otake Y, Sakamoto T et al. Indications for and technical aspects of colorectal endoscopic submucosal dissection. Gut Liver 2013; 7: 263-269

[7] Kajiwara H, Umemura S, Mukai M et al. Adenocarcinoma arising within a colonic diverticulum. Pathol Int 1996; 46: 538- 539

[8] Ritsuno H, Sakamoto N, Osada T et al. Large superficial tumor of the colon involving a diverticulum removed by endoscopic submucosal dissection. Gastrointest Endosc 2015; 82: 751

[9] Kobara H, Mori H, Rafiq K et al. A peripheral approach allowing successful endoscopic submucosal dissection for early colorectal carcinoma near the diverticula. Rev Esp Enferm Dig 2015; 107: 378 - 379

[10] Sakamoto T, Abe S, Nakajima T et al. Complete removal of a colonic neoplasm extending into a diverticulum with hybrid endoscopic submucosal dissection-mucosal resection and endoscopic band ligation. Endoscopy 2015; 47: (Suppl. 01): E295-E296

[11] Kato M, Uraoka T, Wada M et al. Laterally spreading tumor involving a colon diverticulum successfully resected by endoscopic submucosal dissection. Gastrointest Endosc 2016; 84: 191 - 192

[12] Yoshida N, Naito Y, Kishimoto M. Endoscopic submucosal dissection of T1 cancer with colonic diverticulum by pocket-creation method. Dig Endosc 2017; 29: 726 - 727

[13] Takasago T, Kuwai T, Yamaguchi T et al. Endoscopic submucosal dissection with a scissors-type knife for post-EMR recurrence tumor involving the colon diverticulum. VideoGIE 2017; 2: 211-212

[14] Iwatsubo T, Uedo N, Yamasaki Y et al. Traction-assisted colorectal endoscopic submucosal dissection by use of clip and line for a neoplasm involving colonic diverticulum. VideoGIE 2017; 2: 337 - 338

[15] Kudo S, Tamura S, Nakajima T et al. Diagnosis of colorectal tumorous lesions by magnifying endoscopy. Gastrointest Endosc 1996; 44: $8-14$

[16] Oyama T. Counter traction makes endoscopic submucosal dissection easier. Clin Endosc 2012; 45: 375 - 378

[17] Parra-Blanco A, Nicolas D, Arnau MR et al. Gastric endoscopic submucosal dissection assisted by a new traction method: the clip-band technique. A feasibility study in a porcine model (with video). Gastrointest Endosc 2011; 74: 1137-1141

[18] Karita M, Tada M, Okita K et al. Endoscopic therapy for early colon cancer: the strip biopsy resection technique. Gastrointest Endosc 1991; 37: $128-132$

[19] Hamilton S, Aaltonen L. World Health Organization Classification of Tumours: pathology and genetics of tumours of the digestive system. Lyon: IARC Press; 2000

[20] Tanaka S, Sano Y. Aim to unify the narrow band imaging (NBI) magnifying classification for colorectal tumors: current status in Japan from a summary of the consensus symposium in the 79th Annual Meeting of the Japan Gastroenterological Endoscopy Society. Dig Endosc 2011; 23: (Suppl. 01): $131-139$

[21] Hayashi N, Tanaka S, Hewett DG et al. Endoscopic prediction of deep submucosal invasive carcinoma: validation of the narrow-band imaging international colorectal endoscopic (NICE) classification. Gastrointest Endosc 2013; 78: 625-632

[22] Saito Y, Uraoka T, Yamaguchi Y et al. A prospective, multicenter study of 1111 colorectal endoscopic submucosal dissections (with video). Gastrointest Endosc 2010; 72: 1217-1225

[23] Oka S, Tanaka S, Saito Y et al. Local recurrence after endoscopic resection for large colorectal neoplasia: a multicenter prospective study in Japan. Am J Gastroenterol 2015; 110: 697 - 707

[24] Yamada M, Saito Y, Takamaru H et al. Long-term clinical outcomes of endoscopic submucosal dissection for colorectal neoplasms in 423 cases: a retrospective study. Endoscopy 2017; 49: 233-242 
[25] Shigita K, Oka S, Tanaka S et al. Long-term outcomes after endoscopic submucosal dissection for superficial colorectal tumors. Gastrointest Endosc 2017; 85: $546-553$

[26] Schmidt A, Beyna T, Schumacher B et al. Colonoscopic full-thickness resection using an over-the-scope device: a prospective multicentre study in various indications. Gut 2018; 67: 1280 - 1289

[27] Moss A, Williams SJ, Hourigan LF et al. Long-term adenoma recurrence following wide-field endoscopic mucosal resection (WF-EMR) for advanced colonic mucosal neoplasia is infrequent: results and risk factors in 1000 cases from the Australian Colonic EMR (ACE) study. Gut 2015; 64: $57-65$

[28] Yamada M, Saito Y, Sakamoto T et al. Endoscopic predictors of deep submucosal invasion in colorectal laterally spreading tumors. Endoscopy 2016; 48: $456-464$

[29] Sakamoto T, Saito Y, Matsuda T et al. Treatment strategy for recurrent or residual colorectal tumors after endoscopic resection. Surg Endosc 2011; 25: $255-260$

[30] Mori H, Tsushimi T, Kobara H et al. Endoscopic management of a rare granulation polyp in a colonic diverticulum. World J Gastroenterol 2013; 19: 9481 - 9484
[31] Carmo J, Marques S, Chapim I et al. Elastic band ligation for the removal of a colonic tubular adenoma in a diverticulum. Endoscopy 2015; 47: (Suppl. 01): E490-491

[32] Pinho R, Oliveira M, Mascarenhas-Saraiva M. Endoscopic full-thickness resection of an inverted colonic diverticulum with intraepithelial neoplasia using the ligate-and-let-go technique. Clin Gastroenterol Hepatol 2015; 13: A33-A34

[33] Shakhatreh MH, Hair C, Shaib YH et al. Removal of a colonic polyp in a diverticulum: a novel use of the over-the-scope clip device. Gastrointest Endosc 2015; 81: 756

[34] Valli PV, Kaufmann M, Vrugt B et al. Endoscopic resection of a diverticulum-arisen colonic adenoma using a full-thickness resection device. Gastroenterology 2014; 147: 969 -971

[35] Kiriyama S, Saito Y, Yamamoto S et al. Comparison of endoscopic submucosal dissection with laparoscopic-assisted colorectal surgery for early-stage colorectal cancer: a retrospective analysis. Endoscopy 2012; 44: $1024-1030$ 